University of Nebraska - Lincoln

DigitalCommons@University of Nebraska - Lincoln

\title{
Insecticidal Effect of Diatomaceous Earth Against Three Species of Stored-Product Psocids on Maize, Rice, and Wheat
}

Christos G. Athanassiou

Agricultural University of Athens, athanas@aua.gr

Frank H. Arthur

USDA-ARS, frank.arthur@ars.usda.gov

George P. Opit

USDA-ARS

James E. Throne

USDA-ARS, Manhattan, KS, james.throne@ars.usda.gov

Follow this and additional works at: https://digitalcommons.unl.edu/usdaarsfacpub

Athanassiou, Christos G.; Arthur, Frank H.; Opit, George P.; and Throne, James E., "Insecticidal Effect of Diatomaceous Earth Against Three Species of Stored-Product Psocids on Maize, Rice, and Wheat" (2009). Publications from USDA-ARS / UNL Faculty. 2036.

https://digitalcommons.unl.edu/usdaarsfacpub/2036

This Article is brought to you for free and open access by the U.S. Department of Agriculture: Agricultural Research Service, Lincoln, Nebraska at DigitalCommons@University of Nebraska - Lincoln. It has been accepted for inclusion in Publications from USDA-ARS / UNL Faculty by an authorized administrator of DigitalCommons@University of Nebraska - Lincoln. 


\title{
Insecticidal Effect of Diatomaceous Earth Against Three Species of Stored-Product Psocids on Maize, Rice, and Wheat
}

\author{
CHRISTOS G. ATHANASSIOU, ${ }^{1,2}$ FRANK H. ARTHUR, ${ }^{2}$ GEORGE P. OPIT, $, 2,3$ \\ AND JAMES E. THRONE ${ }^{2}$
}

\begin{abstract}
J. Econ. Entomol. 102(4): 1673-1680 (2009)
ABSTRACT We evaluated the efficacy of three diatomaceous earth (DE) formulations, Dryacide, Protect-It, and Insecto, against three Psocoptera species, Liposcelis entomophila (Enderlein) (Liposcelididae), Lepinotus reticulatus Enderlein (Trogiidae), and Liposcelis decolor (Pearman), in the laboratory. Bioassays were conducted in three grain commodities, wheat, rice and maize, at $30^{\circ} \mathrm{C}$ and $75 \% \mathrm{RH}$, and the DEs were applied at the recommended dose rates of $1,000,400$, and $500 \mathrm{ppm}$ for Dryacide, Protect-It, and Insecto, respectively. Differences in adult mortality were found among grains and DEs for L. entomophila and L. reticulatus, but these trends were not consistent for all combinations tested. Type of grain and DE did not affect $L$. decolor mortality significantly. Moreover, mortality increased with increasing exposure time for L. entomophila and L. reticulatus, but there was no effect of exposure time on L. decolor. After $7 \mathrm{~d}$ of exposure, mortalities of L. entomophila, L. reticulatus, and $L$. decolor were 56,55 , and $40 \%$, respectively, and the respective mortality levels after $14 \mathrm{~d}$ were 63 , 71 , and $42 \%$. Progeny production after $30 \mathrm{~d}$ was significantly suppressed for all species in the treated grains. However, progeny production was still high in the treated grains and reached 54, 42, and 76 individuals/10 g of grain for L. entomophila, L. reticulatus, and L. decolor, respectively. Progeny production did not vary with commodity. Our results suggest that DEs, when used alone, will not provide effective control of psocids.
\end{abstract}

KEY WORDS Liposcelis entomophila, Lepinotus reticulatus, Liposcelis decolor, grains, inert dusts

Psocoptera, also known as psocids, until recently were considered pests of minor economic importance in stored products partly because of their small size, which makes them difficult to detect in storage facilities, and because little information is available on their eco-biology. However, psocids have become an emerging problem during the last decade in both stored grain and grain processing facilities (Nayak 2006, Throne et al. 2006). The key psocid species associated with grain and related products in several parts of the world are Liposcelis entomophila (Enderlein) (Psocoptera: Liposcelididae), Liposcelis decolor (Pearman), Liposcelis bostrychophila Badonnel, Liposcelis paeta Pearman, and Lepinotus reticulatus Enderlein (Psocoptera: Trogiidae) (Sinha 1988; Rees and Walker 1990; Lienhard and Smithers 2002; Nayak et al. 2002a, b; Kucerova and Horak 2004; Nayak 2006; Throne et al. 2006; Nayak and Daglish 2007).

Mention of trade names or commercial products in this article is solely for the purpose of providing specific information and does not imply recommendation or endorsement by the U.S. Department of Agriculture.

${ }^{1}$ Corresponding author: Laboratory of Agricultural Zoology and Entomology, Agricultural University of Athens, 75 Iera Odos, 11855 Athens, Greece (e-mail: athanas@aua.gr).

${ }^{2}$ USDA-ARS, Grain Marketing and Production Research Center, 1515 College Ave., Manhattan KS 66502-2736.

${ }^{3}$ Oklahoma State University, Department of Entomology and Plant Pathology, 127 Noble Research Center, Stillwater OK 74078-3033.
Until recently, the control measures that were used against other stored product insects, such as Coleoptera and Lepidoptera, were considered sufficient for the simultaneous control of psocids, despite the fact that no data were available for the evaluation of specific control measures against psocids. Recent studies clearly indicate that psocids show a remarkable tolerance to some of the currently used insecticides at application rates that are usually effective against other stored product insect species. For example, the insect growth regulator (IGR) methoprene, which is very effective against the the lesser grain borer, Rhyzopertha dominica (F.) (Coleoptera: Bostrichidae), which is a major beetle pest of stored wheat (Arthur 2004b), was not very effective against $L$. bostrychophila, L. entomophila, and L. paeta (Nayak et al. 1998). Also, L. paeta and L. entomophila were found to be resistant to fenitrothion, chlorpyrifos-methyl, pirimiphos-methyl, deltamethrin, bioresmethrin, and carbaryl, whereas a survey of field populations of these species suggested that psocid tolerance to protectant insecticides is a natural phenomenon and not related to resistance (Nayak et al. 1998). Other studies have shown that Liposcelis spp. are resistant to permethrin and pirimiphos-methyl applied as structural treatments (Collins et al. 2000, Nayak et al. 2002a). Spinosad, which effectively controls $R$. dominica, is unable to completely control $L$. entomophila, $L$. 
bostrychophila, L. paeta, and L. decolor adults and progeny (Nayak and Daglish 2007). Psocids can develop high levels of resistance to phosphine, and in Australia, this has elevated their pest status to that of the major beetle pests (Nayak et al. 2003). There is currently no information available on the effectiveness of contact insecticides or fumigants against $L$. reticulatus.

One of the most well-studied alternatives to traditional neurotoxic grain protectants is the use of diatomaceous earths (DEs). DEs have been evaluated by several researchers against a wide range of stored product insect pests, such as beetles (Fields and Korunic 2000; Subramanyam and Roesli 2000; Arthur 2000, 2003, 2004a, b; Athanassiou et al. 2003, 2004, 2005; Kavallieratos et al. 2005), moths (Subramanyam et al. 1998, Athanassiou 2006), and mites (Cook and Armitage 1999, Palyvos et al. 2006). DEs act in the cuticle, causing desiccation and death through water loss (Korunic 1998). Therefore, it is generally expected that soft-bodied species or life stages of the same species will be more susceptible to DEs. For example, Vayias and Athanassiou (2004) found that larvae of the confused flour beetle, Tribolium confusum Jacquelin Du Val (Coleoptera: Tenebrionidae), were considerably more susceptible than adults after exposure to the DE formulation SilicoSec on wheat or flour. Because psocids are considered soft-bodied insects, DEs could be good candidates for their control. Despite this, there is almost no information on the effect of DEs on psocids. In this study, we evaluated three commercially available DE formulations against $L$. entomophila, L. decolor, and L. reticulatus on maize, rice, and wheat.

\section{Materials and Methods}

Commodities. Wheat (variety Mexa), rice (variety Thaibonnet), and maize (variety Dias) were used in the test. The initial moisture content of the three grains, as determined by a moisture meter (Multigrain CAC II; Dickey-John, Aurora, IL), ranged between 11.9 and $12.6 \%$. All grains were placed in incubators for $21 \mathrm{~d}$ to equilibrate to the desired conditions before the beginning of the experiments (see below). After this interval, the mean moisture content of the grains was $13.2 \%$.

DE Formulations. Three commercially available DE formulations were used in the tests. These were (1) Insecto (Insecto Natural Products, Costa Mesa, CA), a DE that contains $10 \%$ food-grade additives; (2) Protect-It (Hedley Technologies, Mississauga, Ontario, Canada), which contains $90 \% \mathrm{DE}$ and $10 \%$ silica aerogel; and (3) Dryacide (Entosol, Roselands, New South Wales, Australia), which also contains $90 \%$ DE and $10 \%$ silica gel. The label rates for Insecto, ProtectIt, and Dryacide are 500, 400, and 1,000 ppm, respectively; these rates were used in the tests. The above DE formulations are registered in the United States and in other parts of the world as grain protectants and have been proven effective against several stored product insect species.
Insects. The cultures of L. entomophila, L. reticulatus, and L. decolor were obtained from the Biological Research Unit, Grain Marketing and Production Research Center, USDA-ARS, Manhattan, KS. The cultures were maintained at $30^{\circ} \mathrm{C}, 75 \% \mathrm{RH}$, and continuous darkness on a mixture of $97 \%$ cracked wheat, $2 \%$ rice krispies, and 1\% brewer's yeast. Two-week-old adult females were obtained by putting late-instar nymphs in 0.5-liter glass canning jars containing $250 \mathrm{~g}$ of psocid diet. After $3 \mathrm{wk}$, the adults in the jars were $\approx 2$ wk old, and females were removed and used in the bioassays. Psocids used for starting cultures of L. entomophila and L. reticulatus were obtained in 2004 from steel bins containing wheat at the Grain Marketing and Production Research Center; psocids for cultures of $L$. decolor were obtained in 2006 from the same location in steel bins containing wheat. Voucher specimens of $L$. reticulatus, $L$. entomophila, and $L$. decolor were deposited in the Kansas State University Museum of Entomological and Prairie Arthropod Research under lots 181,182 , and 205, respectively.

Bioassays. All tests were conducted at $30^{\circ} \mathrm{C}, 75 \% \mathrm{RH}$, and continuous darkness. The desired relative humidity was maintained by using a saturated sodium chloride solution (Greenspan 1977). Lots of $0.5 \mathrm{~kg}$ of the three grains were placed in 0.5-liter cylindrical glass jars, treated with the respective DE quantities, and shaken manually for 3 min to achieve equal distribution of the dust to the entire grain mass (Kavallieratos et al. 2005). From each lot, nine 10-g samples were taken and placed in cylindrical glass vials $(2.5 \mathrm{~cm}$ in diameter, $8 \mathrm{~cm}$ high), which were closed, apart from a hole ( $1 \mathrm{~cm}$ in diameter) covered with fine mesh at the top to allow aeration. Ten females of $L$. entomophila were placed in each vial. The same procedure was repeated for the other psocid species. The vials were placed in incubators set at the conditions mentioned above. An additional set of jars and vials were used for each grain, which served as untreated controls. After $7 \mathrm{~d}$, three of the nine vials were opened, and psocid mortality was determined, whereas the mortality was checked $1 \mathrm{wk}$ later in another three vials. Progeny production was measured $30 \mathrm{~d}$ after the introduction of the parental adults in the last three vials. Temperature and humidity during the experiment were monitored using HOBO data loggers (HOBO H8; Onset Computers, Bourne, MA). The entire experiment was repeated twice for a total of three replications.

Data Analysis. Generally, control mortality ranged between 0 and 20\% (0-2 adults/vial, in most cases 0$)$, and treatment mortalities were corrected using the Abbott's formula (1925). The mortality data were analyzed separately for each species in a three-way analysis of variance (ANOVA) for commodity, exposure interval, and DE treatment as main effects by using the JMP IN software v.5.1 (Sall et al. 2001). The same procedure was followed (without exposure) for progeny production data, but progeny production in the control (untreated) grains was included in the analysis. Means were separated by the Tukey-Kramer hon- 
Table 1. ANOVA results for main effects and interactions for mortality of three psocid species (total df $=\mathbf{5 3}$ )

\begin{tabular}{|c|c|c|c|c|c|c|c|}
\hline \multirow[t]{2}{*}{ Source } & \multirow[t]{2}{*}{$\mathrm{df}$} & \multicolumn{2}{|c|}{$\begin{array}{c}\text { L. } \\
\text { entomophila } \\
\end{array}$} & \multicolumn{2}{|c|}{ L. reticulatus } & \multicolumn{2}{|c|}{ L. decolor } \\
\hline & & $F$ & $P$ & $F$ & $P$ & $F$ & $P$ \\
\hline $\mathrm{DE}$ & 2 & 8.6 & $<0.01$ & 3.4 & 0.04 & 2.5 & 0.09 \\
\hline Grain & 2 & 3.4 & 0.04 & 9.4 & $<0.01$ & 0.8 & 0.44 \\
\hline Exposure & 1 & 12.6 & $<0.01$ & 38.7 & $<0.01$ & 1.8 & 0.19 \\
\hline $\mathrm{DE} \times$ grain & 4 & 2.8 & 0.04 & 5.5 & $<0.01$ & 0.2 & 0.94 \\
\hline $\mathrm{DE} \times$ exposure & 2 & 0.7 & 0.48 & 1.6 & 0.21 & 0.1 & 0.89 \\
\hline Grain $\times$ exposure & 2 & 9.2 & $<0.01$ & 3.4 & 0.04 & 0.6 & 0.53 \\
\hline $\begin{array}{l}\mathrm{DE} \times \text { grain } \times \\
\text { exposure }\end{array}$ & 4 & 5.7 & $<0.01$ & 5.7 & $<0.01$ & 0.6 & 0.64 \\
\hline
\end{tabular}

estly significant difference (HSD) test at $\alpha=0.05$ (Sokal and Rohlf 1995).

\section{Results}

Liposcelis entomophila. For mortality counts, all main effects and all interactions were significant at $P<$ 0.05 , with the exception of DE $\times$ exposure (Table 1 ). Generally, mortality increased with increasing exposure (Fig. 1). After $7 \mathrm{~d}$ of exposure, mortality on maize and wheat treated with Dryacide was significantly higher than for the other two DEs (Fig. 1). However, $\approx 35 \%$ of the exposed adults were still alive. No significant differences were found among DEs on rice. Mortality of L. entomophila reached $79 \%$ for Dryacide applied to wheat after $14 \mathrm{~d}$ of exposure (Fig. 1). No significant differences among DEs were found on the other two grains, where mortality ranged between 60 and $75 \%$. Only DE treatment was significant for progeny production (Table 2 ). Significantly fewer progeny were produced in the treated grains than in the controls, but there were no significant differences among the three DEs (Table 3).

Lepinotus reticulatus. As in the case of L. entomophila, all main effects and interactions for mortality were significant, with the exception of $\mathrm{DE} \times$ exposure (Table 1). No significant differences were noted among the three DEs after $7 \mathrm{~d}$ of exposure on wheat, and mortality reached $79 \%$ (Fig. 2). However, mortality did not exceed 47 and $59 \%$ for rice and maize, respectively. Mortality was increased after $14 \mathrm{~d}$, even for rice and maize (Fig. 2). No significant differences were noted among DEs on wheat and rice, and mortality ranged between 81 and $89 \%$. Significantly more adults were dead in maize treated with Dryacide than with Protect-It; mortality after a 14-d exposure to Dryacide applied to maize reached $93 \%$. As in the case of L. entomophila, only treatment was significant for progeny production (Table 2 ). Significantly fewer progeny were produced in the treated than in the untreated commodities, but there were no significant differences among the three DEs (Table 3).

Liposcelis decolor. For mortality, neither main effects nor interactions were significant (Table 1). Generally, this species was less susceptible to DE than the other two species (Fig. 3). Mortality did not exceed 44 or $47 \%$ after 7 or $14 \mathrm{~d}$, respectively, on any of the commodities tested. As for the other two species, only

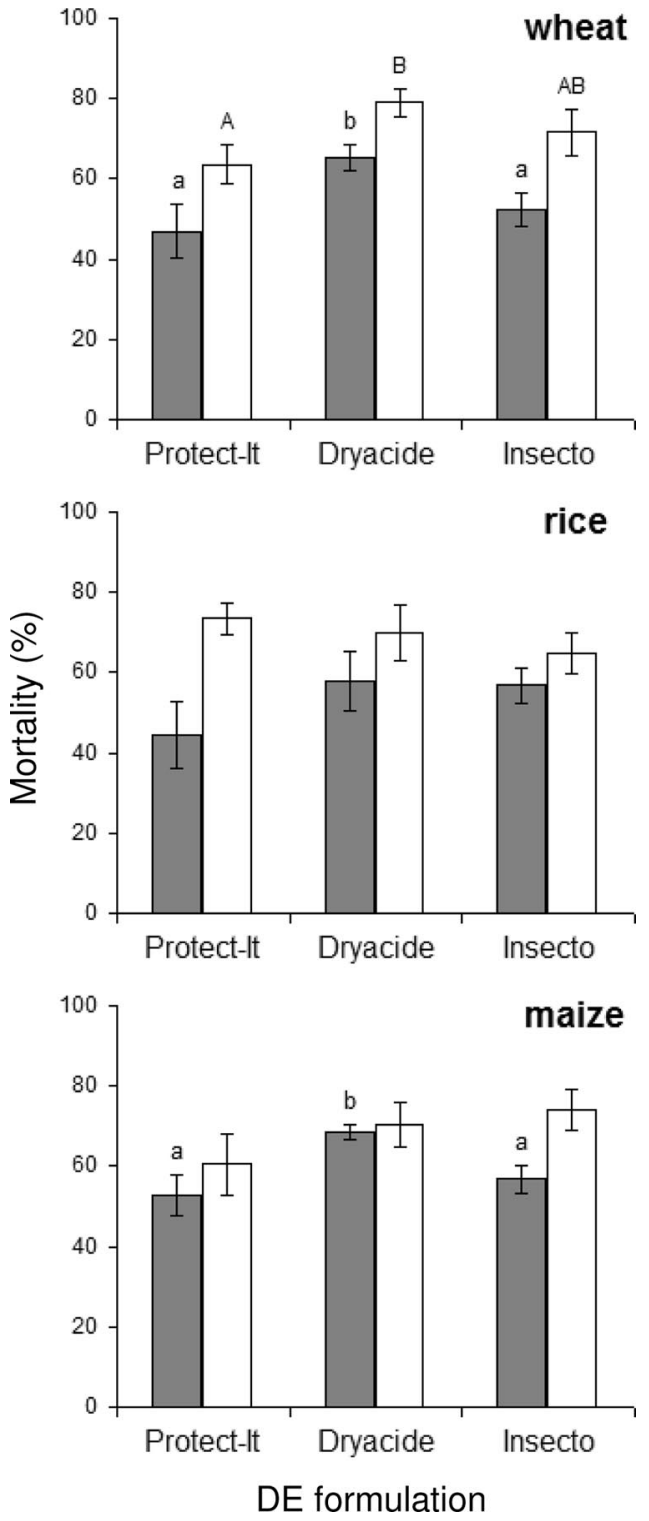

Fig. 1. Mean (\%) mortality $( \pm \mathrm{SE})$ of L. entomophila adults on three grains treated with three DE formulations after 7 (gray columns) and $14 \mathrm{~d}$ (white columns) of exposure (within each grain and exposure, means followed by the same letter are not significantly different; where no letters exist, no significant differences were noted; HSD test at $\alpha=0.05$ ).

treatment was significant for progeny production (Table 2). Significantly fewer progeny were produced in the treated than in the untreated commodities, but there were no significant differences among the three DEs (Table 3).

\section{Discussion}

DEs when used alone will not provide effective control of psocids, and differences exist in the insecticidal efficacy of the different DEs. For example, grain 
Table 2. ANOVA results for main effects and interaction for progeny production of three psocid species (total df $=35$ )

\begin{tabular}{|c|c|c|c|c|c|c|c|}
\hline \multirow[t]{2}{*}{ Source } & \multirow[t]{2}{*}{$\mathrm{df}$} & \multicolumn{2}{|c|}{$\begin{array}{c}\text { L. } \\
\text { entomophila } \\
\end{array}$} & \multicolumn{2}{|c|}{$\begin{array}{c}\text { L. } \\
\text { reticulatus }\end{array}$} & \multicolumn{2}{|c|}{ L. decolor } \\
\hline & & $F$ & $P$ & $F$ & $P$ & $F$ & $P$ \\
\hline $\begin{array}{l}\text { Treatment (DEs } \\
\quad \text { or control) }\end{array}$ & 3 & 18.3 & $<0.01$ & 36.8 & $<0.01$ & 29.1 & $<0.01$ \\
\hline Grain & 2 & 1.5 & 0.23 & 0.6 & 0.52 & 0.9 & 0.39 \\
\hline Treatment $\times$ grain & 6 & 0.7 & 0.61 & 1.0 & 0.42 & 1.2 & 0.34 \\
\hline
\end{tabular}

type and DE used and exposure time did not affect $L$. decolor mortality significantly, but this was not the case for L. entomophila and L. reticulatus. Differences in insecticidal efficacy of different DEs has been shown for other stored product pests (Korunic 1997, 1998; Fields and Korunic 2000; Subramanyam and Roesli 2000). Using adults of the larger grain borer, Prostephanus truncatus (Horn) (Coleoptera: Bostrichidae), which are considered extremely tolerant to DEs (Stathers et al. 2002), Athanassiou et al. (2007) found that an abamectin-enhanced DE was more effective than Protect-It or PyriSec (a pyrethrum-enhanced DE). Korunic (1997) noted that some of the most crucial factors that determine the efficacy of a given $\mathrm{DE}$ are silica content, particle size, $\mathrm{pH}$, and diatom shape.

Generally, DEs are considered to be less effective on maize than on wheat or rice against stored grain beetle pests (Subramanyam and Roesli 2000; Athanassiou et al. 2003, 2005). Athanassiou et al. (2003) showed that the DE SilicoSec was less effective on maize than on rice and barley against adults of the rice weevil, Sitophilus oryzae L. (Coleoptera: Curculionidae). Reduced retention of DE particles in the maize kernels in comparison with other grain commodities may be one of the basic reasons for these dissimilar results among grains (Kavallieratos et al. 2005).

Our study has shown that DE suppressed progeny production (19-39\% in comparison with the progeny in the controls) for all species over a 30-d exposure interval. Despite this, progeny production in the treated grain remained rather high even when parental mortality was high. L. reticulatus females were very susceptible to DEs, with an average mean mortality for all grains and DEs of $85 \%$ after $14 \mathrm{~d}$, yet progeny production was still rather high at $28-42$ progeny per vial. In fact, progeny production for this species in the treated commodities was comparable to that of $L$. entomophila, despite the greater parental mortality for L. entomophila compared with L . reticulatus. In addition, it should be noted that we observed progeny for all species during the 14-d mortality counts.

Opit and Throne (2008) found that larger numbers of both L. entomophila and L. reticulatus are produced on rice and wheat than on maize. In this study, a similar pattern was observed in the control vials, but commodity had no effect in the treated grains, indicating that progeny suppression was primarily caused by the effect of DE and not caused by a complementary effect between DE and the type of grain. Practically, DEs may not be effective as long-term protectants against psocids, even in the most susceptible species, because one of the key characteristics of a successful protectant is progeny suppression.

In the only report thus far on the effect of DEs against psocids, Yang et al. (2003) reported 100\% mortality of $L$. entomophila after exposure to surfaces treated with Protect-It at $65 \% \mathrm{RH}$ or lower, whereas mortality was reduced with increase of $\mathrm{RH}$ above this level. However, ours is the first study in which efficacy of DEs as an admixture with grain is tested against psocids. These results indicate that the three species tested vary in their susceptibility to DEs, with $L$. decolor being the most DE-tolerant species. It should be noted that the doses tested here cause $100 \%$ mortality to other stored grain insect species. Athanassiou et al. (2005) reported that $500 \mathrm{ppm}$ of the DE SilicoSec caused $100 \%$ mortality and complete suppression of progeny production on wheat against $S$. oryzae. Nevertheless, we found that some individuals of even the most susceptible psocid species could survive $14 \mathrm{~d}$ of exposure to DE.

DEs are generally very effective for another group of soft-bodied stored-product pest species, mites. Palyvos et al. (2006) found that $500 \mathrm{ppm}$ of the DE SilcoSec on wheat was highly effective against Tyrophagus putrescentiae (Schrank) (Astigmata: Acaridae), whereas mortality was low for its predator Cheyletus malaccensis (Oudemans) (Prostigmata: Cheyletidae). Cook and Armitage (1999) found that $1,000 \mathrm{ppm}$ of Dryacide provided $100 \%$ inhibition of

Table 3. Mean progeny production (no. of individuals/vial \pm SE) for three psocid species on three commodities (means for a species within each column followed by the same letter are not significantly different; HSD test at $\alpha=0.05$ )

\begin{tabular}{|c|c|c|c|c|}
\hline Species & Treatment & Wheat & Rice & Maize \\
\hline \multirow[t]{4}{*}{ L. entomophila } & Control & $153.7 \pm 36.3 \mathrm{a}$ & $201.1 \pm 28.4 \mathrm{a}$ & $117.2 \pm 20.2 \mathrm{a}$ \\
\hline & Protect-It & $37.3 \pm 4.6 \mathrm{~b}$ & $54.4 \pm 12.8 b$ & $40.0 \pm 5.2 \mathrm{~b}$ \\
\hline & Dryacide & $43.5 \pm 6.9 \mathrm{~b}$ & $42.6 \pm 7.4 b$ & $32.3 \pm 4.1 b$ \\
\hline & Insecto & $49.1 \pm 9.0 b$ & $38.8 \pm 7.7 \mathrm{~b}$ & $29.4 \pm 4.4 \mathrm{~b}$ \\
\hline \multirow[t]{4}{*}{ L. reticulatus } & Control & $128.0 \pm 21.2 \mathrm{a}$ & $172.4 \pm 39.0 \mathrm{a}$ & $92.9 \pm 17.7 \mathrm{a}$ \\
\hline & Protect-It & $34.9 \pm 4.1 \mathrm{~b}$ & $28.0 \pm 6.3 \mathrm{~b}$ & $27.7 \pm 3.3 b$ \\
\hline & Dryacide & $30.1 \pm 3.9 b$ & $37.4 \pm 6.8 b$ & $36.3 \pm 4.5 b$ \\
\hline & Insecto & $41.9 \pm 8.8 b$ & $34.6 \pm 5.6 \mathrm{~b}$ & $32.4 \pm 4.0 \mathrm{~b}$ \\
\hline \multirow[t]{4}{*}{ L. decolor } & Control & $194.9 \pm 41.5 \mathrm{a}$ & $217.5 \pm 34.7 \mathrm{a}$ & $181.0 \pm 28.5 \mathrm{a}$ \\
\hline & Protect-It & $60.3 \pm 12.3 b$ & $79.3 \pm 18.4 b$ & $53.4 \pm 9.5 b$ \\
\hline & Dryacide & $76.2 \pm 17.3 b$ & $49.2 \pm 13.2 b$ & $59.4 \pm 12.4 \mathrm{~b}$ \\
\hline & Insecto & $61.3 \pm 10.2 b$ & $64.3 \pm 16.7 \mathrm{~b}$ & $42.0 \pm 8.7 \mathrm{~b}$ \\
\hline
\end{tabular}




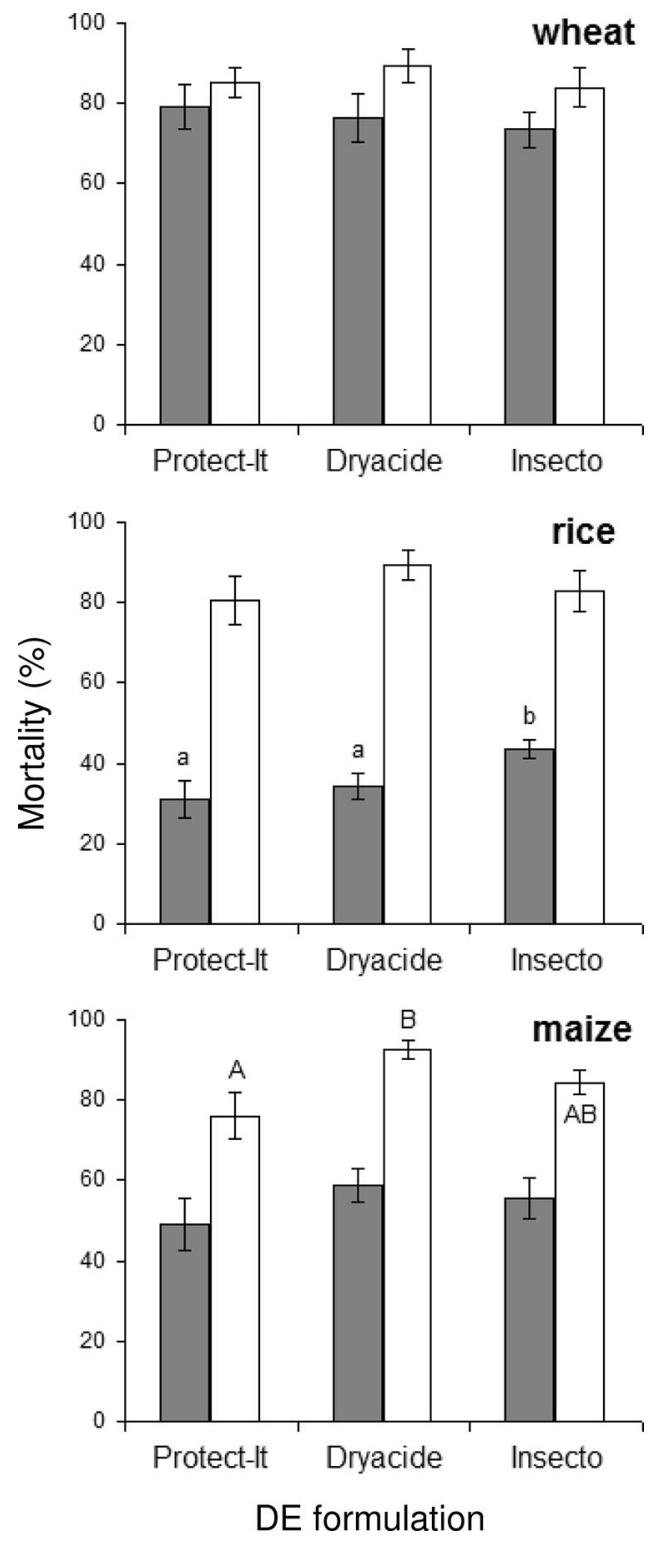

Fig. 2. Mean (\%) mortality ( $\pm \mathrm{SE})$ of L. reticulatus adults on three grains treated with three DE formulations after 7 (gray columns) and $14 \mathrm{~d}$ (white columns) of exposure (within each grain and exposure, means followed by the same letter are not significantly different; where no letters exist, no significant differences were noted; HSD test at $\alpha=0.05$ ).

population growth of Acarus siro L. (Astigmata: Acaridae), but they reported that higher doses were needed for Lepidoglyphus destructor (Schrank) (Astigmata: Glycyphagidae). Hence, cuticle thickness may not be the major parameter that affects susceptibility to desiccants, such as DEs.

Research needs to be conducted to determine the reasons for the low susceptibility of psocids to DEs. However, the nature of the cuticle in psocids may be one possible reason. Lord and Howard (2004) found
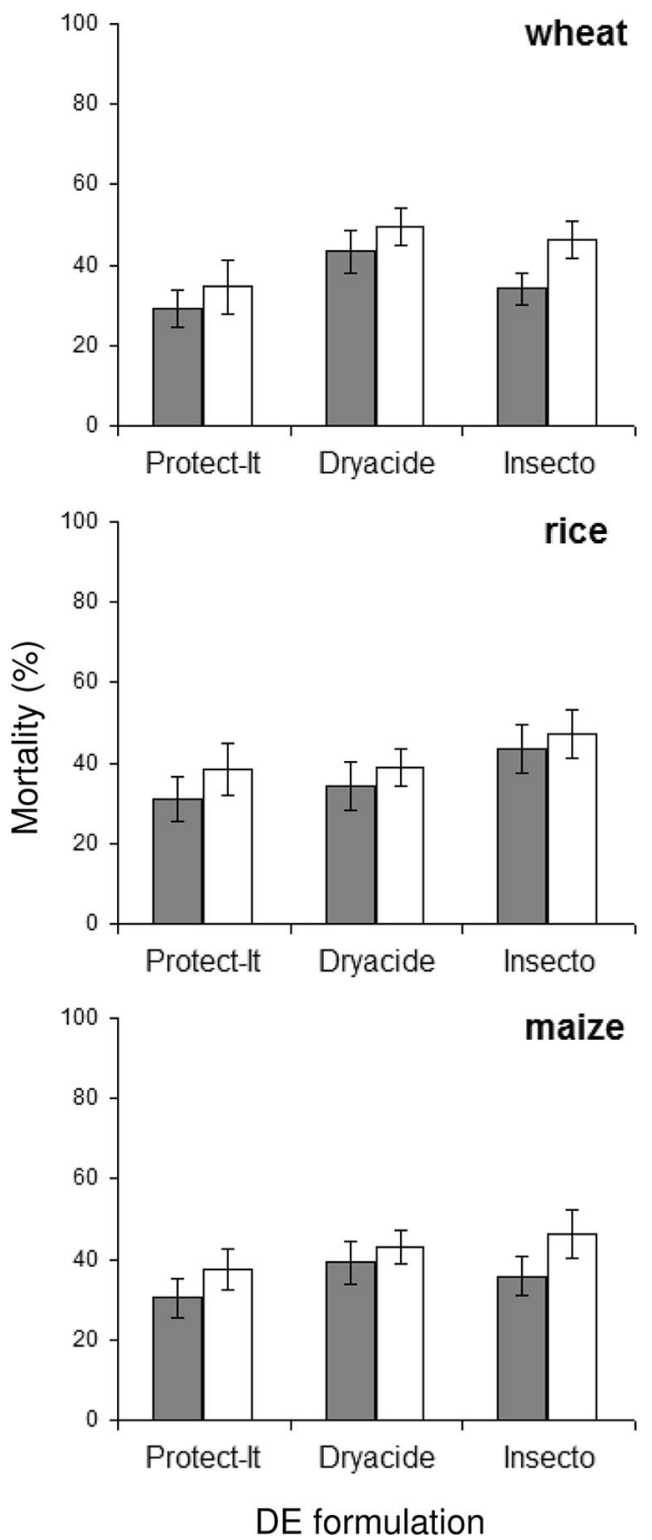

Fig. 3. Mean (\%) mortality $( \pm \mathrm{SE})$ of $L$. decolor adults on three grains treated with three DE formulations after 7 (gray columns) and $14 \mathrm{~d}$ (white columns) of exposure.

that Liposcelis bostrychophila was remarkably tolerant to three species of entomopathogenic fungi at doses that were lethal to other stored product insects, such as beetles (Kavallieratos et al. 2006, Athanassiou and Steenberg 2007). The authors suggest that the unusual cuticular lipid composition of this species may play a role in antifungal defense. Moreover, Howard and Lord (2003) noted that this composition may protect psocids from surface abrasion and that low molecular weight compounds may help the insects in sloughing off dust.

Another possible reason for low susceptibility to DEs in psocids is the fact that some insect species can 
moderate water loss. For example, using a water-loss moderation mechanism located in the rectal portion of the hindgut, the larvae of the yellow mealworm, Tenebrio molitor L. (Coleoptera: Tenebrionidae), remain unaffected after exposure to DE-treated substrates (Machin 1975, Mewis and Ulrichs 2001). For other species, this mechanism is located in the mouth, such as in the cockroach Arenivaga investigata Friauf and Edney (Blattaria: Polyphagidae) (O'Donnell 1977). In the case of psocids, Rudolph (1982b), using Psyllipsocus ramburi Selys-Longchamps (Psocoptera: Psyllipsocidae) as a model species, reported that Psocoptera also have an active water vapor uptake mechanism, which is located in the mouthparts and that the hypopharynx is exposed to ambient atmosphere during absorption causing water vapor condensation. Also, this uptake seems to characterize a large number of species of this order, and it is a continuous uptake process directly related to relative humidity levels (Rudolph 1982a). For species of the genus Liposcelis, Knulle and Spadafora (1969) reported that water absorption from the air occurs at relative humidity levels $<58 \%$.

The order of tolerance to the DEs tested was found to be L. decolor $>$ L. entomophila $>$ L. reticulatus. Nayak et al. (2002b) also noted that L. decolor was more tolerant to azamethiphos plus carbaryl compared with L. entomophila, L. bostrychophila, and L. paeta, whereas the same species was also tolerant to chlorpyriphos-methyl. It is also important to point out that even though we used DEs at the labeled application rates during this study, doses between 400 and 1,000 ppm negatively affect some of the physical properties of grains, particularly bulk density (Korunic et al. 1998), which seems to be the main drawback for a more extensive use of DEs (Korunic 1998, Subramanyam and Roesli 2000).

Although this study showed that DEs when used alone will not provide effective control of psocids, it is possible that $\mathrm{DE}$ combined with other insecticides may be much more effective. DEs might be best used in conjunction with other protectants, such as organophosphorous insecticides, which are effective against several psocid species (Nayak et al. 1998, 2002b). Thus far, enhanced DE formulations have proven effective for the control of several stored product beetle species (Arthur 2004a, Athanassiou et al. 2007). Additional experimentation is needed to evaluate the parameters that affect the efficacy of the simultaneous use of neurotoxic insecticides and inert dusts against stored product psocids.

\section{Acknowledgments}

We thank A. Redmon, N. Kisangani, and J. Duff for technical assistance and M. Nayak, C. Greenwood, and R. Grantham for comments on an earlier version of this manuscript. This study was partially funded by the Organisation for Economic Co-operation and Development (OECD), Trade and Agriculture Directorate, Co-operative Research Programme, Biological Resource Management for Sustainable
Agricultural Systems, Project: "Insecticidal effect of diatomaceous earth against stored-product psocids."

\section{References Cited}

Abbott, W. S. 1925. A method of computing the effectiveness of an insecticide. J. Econ. Entomol. 18: 265-267.

Arthur, F. H. 2000. Toxicity of diatomaceous earth to red flour beetles and confused flour beetles (Coleoptera: Tenebrionidae): effects of temperature and relative humidity. J. Econ. Entomol. 93: 526-532.

Arthur, F. H. 2003. Optimization of inert dusts used as grain protectants as residual surface treatments, pp. 629-634. In P. F. Credland, D. M. Armitage, C. H. Bell, P. M. Cogan, and E. Highley (eds.), Proceedings of the 8th International Working Conference on Stored-Product Protection, 22-26 July 2002, York, UK. CAB International, Wallingford, Oxon, United Kingdom.

Arthur, F. H. 2004a. Evaluation of a new insecticide formulation (F2) as a protectant of stored wheat, maize and rice. J. Stored. Prod. Res. 40: 317-330.

Arthur, F. H. 2004b. Evaluation of methoprene alone or in combination with diatomaceous earth to control Rhyzopertha dominica (Coleoptera: Bostrychidae). J. Stored. Prod. Res. 40: 484-498.

Athanassiou, C. G. 2006. Influence of instar and commodity on insecticidal effect of two diatomaceous earth formulations against larvae of Ephestia kuehniella (Lepidoptera: Pyralidae). J. Econ. Entomol. 99: 1905-1911.

Athanassiou, C. G., and T. Steenberg. 2007. Insecticidal effect of Beauveria bassiana (Balsamo) Vuillemin (Ascomycota: Hypocreales) in combination with three diatomaceous earth formulations against Sitophilus granarius (L.) (Coleoptera: Curculionidae). Biol. Control 40: 411416.

Athanassiou, C. G., N. G. Kavallieratos, F. C. Tsaganou, B. J. Vayias, C. B. Dimizas, and C. T. Buchelos. 2003. Effect of grain type on the insecticidal efficacy of SilicoSec against Sitophilus oryzae (L.) (Coleoptera: Curculionidae). Crop. Protect. 22: 1141-1147.

Athanassiou, C. G., N. G. Kavallieratos, and N. S. Andris. 2004. Insecticidal effect of three diatomaceous earth formulations against adults of Sitophilus oryzae (Coleoptera: Curculionidae) and Tribolium confusum (Coleoptera: Tenebrionidae) on oat, rye and triticale. J. Econ. Entomol. 97: 2160-2167.

Athanassiou, C. G., B. J. Vayias, C. B. Dimizas, N. G. Kavallieratos, A. S. Papagregoriou, and C. T. Buchelos. 2005. Insecticidal efficacy of diatomaceous earth against Sitophilus oryzae (L.) (Coleoptera: Curculionidae) and Tribolium confusum du Val (Coleoptera: Tenebrionidae) on stored wheat: influence of dose rate, temperature and exposure interval. J. Stored. Prod. Res. 41: 47-55.

Athanassiou, C. G., N. G. Kavallieratos, G. G. Peteinatos, S. Petrou, M. Boukouvala, and Z. Tomanovic. 2007. Influence of temperature and humidity on insecticidal effect of three diatomaceous earth formulations against larger grain borer (Coleoptera: Bostrychidae). J. Econ. Entomol. 100: 599-603.

Collins, P. J., M. K. Nayak, and R. Kopittke. 2000. Residual efficacy of four organophosphates on concrete and galvanized steel surfaces against three Liposcelid species (Psocoptera: Liposcelidae) infesting stored products. J. Econ. Entomol. 93: 1357-1363.

Cook, D. A., and D. M. Armitage. 1999. The efficacy of Dryacide, an inert dust, against two species of astigmatid mites, Glycyphagus destructor and Acarus siro, at nine 
temperature and moisture content combinations on stored grain. Exp. Appl. Acarol. 23: 51-63.

Fields, P., and Z. Korunic. 2000. The effect of grain moisture content and temperature on the efficacy of diatomaceous earths from different geographical locations against stored-product beetles. J. Stored. Prod. Res. 36: 1-13.

Greenspan, L. 1977. Humidity fixed points of binary saturated aqueous solutions. J. Res. Natl. Bur. Stand. A 81: $89-96$.

Howard, R. W., and J. C. Lord. 2003. Cuticular lipids of the booklouse, Liposcelis bostrychophila: hydrocarbons, aldehydes, fatty acids, and fatty acid amides. J. Chem. Ecol. 29: 615-627.

Kavallieratos, N. G., C. G. Athanassiou, F. G. Paschalidou, N. S. Andris, and Z. Tomanovic. 2005. Influence of grain type on the insecticidal efficacy of two diatomaceous earth formulations against Rhyzopertha dominica (F.) (Coleoptera: Bostrychidae). Pest. Manag. Sci. 61: 660666.

Kavallieratos, N. G., C. G. Athanassiou, M. P. Michalaki, Y. A. Batta, H. A. Rigatos, F. G. Pashalidou, G. N. Balotis, Z. Tomanovic, and B. J. Vayias. 2006. Effect of the combined use of Metarhizium anisopliae (Metschinkoff) Sorokin (Deuteromycotina: Hyphomycetes) and diatomaceous earth for the control of three stored-product beetle species. Crop. Protect. 25: 418-425.

Knulle, W., and R. R. Spadafora. 1969. Water vapor sorption and humidity relationships in Liposcelis (Insecta: Psocoptera). J. Stored. Prod. Res. 5: 49-52.

Korunic, Z. 1997. Rapid assessment of the insecticidal value of diatomaceous earths without conducting bioassays. J. Stored. Prod. Res. 33: 219-229.

Korunic, Z. 1998. Diatomaceous earths, a group of natural insecticides. J. Stored. Prod. Res. 34: 87-97.

Korunic, Z., S. Cenkowski, and P. Fields. 1998. Grain bulk density as affected by diatomaceous earth and application method. Postharvest Biol. Technol. 13: 81-89.

Kucerova, Z., and P. Horak. 2004. Arthropod infestation in samples of stored seeds in the Czech Republic. Czech J. Genet. Plant. Breed. 40: 11-16.

Lienhard, C., and C. N. Smithers. 2002. Psocoptera (Insecta), World catalogue and bibliography. Museum of Natural History, Geneva, Switzerland.

Lord, J. C., and R. W. Howard. 2004. A proposed role for the cuticular fatty amides of Liposcelis bostrychophila (Psocoptera: Liposcelidae) in preventing adhesion of entomopathogenic fungi with dry conidia. Mycopathologia 158: 211-217.

Machin, J. 1975. Water balance in Tenebrio molitor L larvae; the effect of atmospheric water absorption. J. Comp. Physiol. 101: 121-132.

Mewis, I., and C. Ulrichs. 2001. Action of amorphous diatomaceous earth against different stages of the stored product pests Tribolium confusum, Tenebrio molitor, Sitophilus granarius and Plodia interpunctella. J. Stored. Prod. Res. 37: 153-164.

Nayak, M. K. 2006. Psocid and mite pests of stored commodities: small but formidable enemies, pp. 1061-1073. In I. Lorini, B. Bacaltchuk, H. Beckel, E. Deckers, E. Sundfeld, J. P. dos Santos, J. D. Biagi, J. C. Celaro, L.R.D. A Faroni, L. Bortolini, et al. (eds.), Proceedings of the 9th International Working Conference on Stored-Product Protection, 15-18 October 2006, Campinas. ABRAPOS, Rodovia, Brazil

Nayak, M. K., and G. J. Daglish. 2007. Combined treatments of spinosad and chlorpyrifos-methyl for management of resistant psocid pests (Psocoptera: Liposcelididae) of stored grain. Pest. Manag. Sci. 63: 104-109.
Nayak, M. K., P. J. Collins, and S. R. Reid. 1998. Efficacy of grain protectants and phosphine against Liposcelis bostrychophila, L. entomophila, and L. paeta (Psocoptera: Liposcelidae). J. Econ. Entomol. 91: 1208-1212.

Nayak, M. K., P. J. Collins, and H. Pavic. 2002a. Long-term effectiveness of grain protectants and structural treatments against Liposcelis decolor (Pearman) (Psocoptera: Liposcelididae), a pest of stored products. Pest. Manag. Sci. 58: 1223-1228.

Nayak, M. K., P. J. Collins, and H. Pavic. 2002b. Resistance to phosphine in psocids: Challenges ahead!, pp. 113-118. In E. J. Wright, H. J. Banks, and E. Highley (eds.), Proceedings of the 2nd Australian Postharvest Technical Conference, 1-4 August 2000, Adelaide, Australia.

Nayak, M. K., P. J. Collins, H. Pavic, and R. A. Koppitke. 2003. Inhibition of egg development by phosphine in the cosmopolitan pest of stored products Liposcelis bostrychophila (Psocoptera: Liposcelididae). Pest. Manag. Sci. 59: 1191-1196.

O’Donnell, M. I. 1977. Site of water vapour absorption in the desert cockroach, Arenivaga investigata. Proc. Natl. Acad. Sci. U.S.A. 74: 1757-1760.

Opit, G. P., and J. E. Throne. 2008. Effects of diet on population growth of psocids Lepinotus reticulatus and $\mathrm{Li}$ poscelis entomophila. J. Econ. Entomol. 101: 616-622.

Palyvos, N. E., C. G. Athanassiou, and N. G. Kavallieratos. 2006. Acaricidal effect of a diatomaceous earth formulation against Tyrophagus putrescentiae (Astigmata: Acaridae) and its predator Cheyletus malaccensis (Prostigmata: Cheyletidae). J. Econ. Entomol. 99: 229-236.

Rees, D. P., and A. J. Walker. 1990. The effect of temperature and relative humidity on population growth of three Liposcelis species infesting stored products in tropical countries. Bull. Entomol. Res. 80: 353-358.

Rudolph, D. 1982a. Occurrence, properties and biological implications of the active uptake of water vapour from the atmosphere in Psocoptera. J. Insect. Physiol. 28: 111-121.

Rudolph, D. 1982b. Site, process and mechanism of active uptake of water vapour from the atmosphere in the Psocoptera. J. Insect. Physiol. 28: 205-212.

Sall, J., A. Lehman, and L. Creighton. 2001. JMP start statistics. A guide to statistics and data analysis using JMP and JMP IN software. Duxbury Press, Belmont, CA.

Sinha, R. N. 1988. Population dynamics of Psocoptera in farm-stored grain and oilseed. Can. J. Zool. 66: 2618-2627.

Sokal, R. R., and F. J. Rohlf. 1995. Biometry. 3rd ed. Freeman, New York.

Stathers, T. E., B. M. Mvumi, and P. Golob. 2002. Field assessment of the efficacy and persistence of diatomaceous earths in protecting stored grain on small scale farms in Zimbabwe. Crop. Protect. 21: 1033-1048.

Subramanyam, Bh., and R. Roesli. 2000. Inert dusts, pp. 321380. In Bh. Subramanyam and D. W. Hagstrum (eds.), Alternatives to pesticides in stored-product IPM. Kluwer Academic Publishers, Dordrecht, The Netherlands.

Subramanyam, Bh., N. Madamanchi, and A. S. Norwood. 1998. Effectiveness of Insecto applied to shelled maize against stored-product insect larvae. J. Econ. Entomol. 91: $280-286$.

Throne, J. E., G. P. Opit, and P. W. Flinn. 2006. Seasonal distribution of psocids in stored wheat, pp. 1095-1103. In I. Lorini, B. Bacaltchuk, H. Beckel, E. Deckers, E. Sundfeld, J. P. dos Santos, J. D. Biagi, J. C. Celaro, L.R.D.A. Faroni, L. Bortolini, et al. (eds.), Proceedings of the 9th International Working Conference on Stored-Product Protection, 15-18 October 2006, Campinas. ABRAPOS, Rodovia, Brazil. 
Vayias, B. J., and C. G. Athanassiou. 2004. Factors affecting efficacy of the diatomaceous earth formulation SilicoSec against adults and larvae of the confused beetle Tribolium confusum du Val (Coleoptera: Tenebrionidae). Crop. Protect. 23: 565-573.

Yang, C., L. Xia, and Z. Huaijun. 2003. The effect of relative humidity on the efficacy of the diatomaceous earth Protect-It ${ }^{\mathrm{TM}}$ against L. entomophila (Enderlein) (Psocoptera:
Liposcelidae), pp. 614-616. In P. F. Credland, D. M. Armitage, C. H. Bell, P. M. Cogan, and E. Highley (eds.), Proceedings of the 8th International Working Conference on Stored-Product Protection; 22-26 July 2002, York, United Kingdom. CAB International, Wallingford, Oxon, United Kingdom.

Received 29 September 2008; accepted 16 January 2009. 